\title{
Эмболизация воротной вены чрескожным чресселезеночным доступом у пациентов с распространенными очаговыми заболеваниями печени
}

\author{
В. А. Кондратюк
}

Национальный институт хирургии и трансплантологии имени А. А. Шалимова НАМН Украины, г. Киев

\section{The portal vein embolization, using transcutaneous transsplenic access in patients with extensive focal hepatic diseases}

\author{
V. A. Kondratiuk \\ Shalimov National Institute of Surgery and Transplantology, Kiev
}

\section{Peфepat}

Цель. На основании анализа собственного опыта применения селезеночного портального доступа определить его возможности в качестве альтернативы контрлатеральному чреспеченочному доступу.

Материалы и методы. Проанализированы результаты предоперационной эмболизации ветвей воротной вены (ЭВВВ) у 11 пациентов с распространенными опухолями печени с использованием чресселезеночного портального доступа.

Результаты. Чресселезеночный портальный катетерный доступ прост, безопасен, однако в связи с индивидуальными анатомическими особенностями селезенки этот тип доступа возможен у 61\% пациентов, нуждающихся в нем. Выводы. Чресселезеночный портальный доступ может быть использован у пациентов, нуждающихся в ЭВВВ, которым невозможно выполнить портальный доступ через часть печени, запланированную для удаления.

Ключевые слова: эмболизация воротной вены; обширная резекция печени; чресселезеночный портальный доступ. Abstract

Objective. Basing on analysis of own experience of the splenic portal access application, to determine its possibilities as an alternative to contralateral transhepatic access.

Materials and methods. Results of the preoperative portal veins branches embolization in 11 patients with extensive hepatic tumors, using transsplenic portal access, were analyzed.

Results. Transsplenic portal catheteric access is simple, secure, but because of the spleen individual anatomic peculiarities this kind of access is possible in only $61 \%$ patients, who need it.

Conclusion. Transsplenic portal access may be used in patients, needing the preoperative portal veins branches embolization, to whom it is impossible to perform transhepatic portal access through that part of the organ, which is planned for excision.

Keywords: embolization of portal vein; extensive hepatic resection; transsplenic portal access.

В настоящее время предоперационная ЭВВВ - одна из наиболее эффективных методик увеличения запланированного печеночного остатка у пациентов с распространенными очаговыми заболеваниями печени, являющихся кандидатами на обширную радикальную резекцию печени [1]. Это вмешательство позволяет уменьшить вероятность пострезекционной печеночной недостаточности за счет перераспределения портального кровотока в пользу запланированного печеночного остатка с его последующей викарной гипертрофией и адаптацией к условиям автономного существования [2]. Однако распространение опухолевого процесса в печени, как правило, влечет за собой изменение внутрипеченочной портальной анатомии, что у ряда больных затрудняет либо делает невозможным ипсилатеральный интрапеченочный портальный катетерный доступ. У таких больных большинство авторов применяют контрлатеральный доступ (через ткань запланированного печеночного остатка) [3]. При таком доступе повреждается остающаяся ткань печени, что ухудшает возможность регенерации и повышает вероятность осложнения пре- доперационной ЭВВВ. Ряд авторов в подобных случаях применяет экстрапеченочные портальные доступы, наименее инвазивным из которых является селезеночный, предполагающий проведение катетера через ткань селезенки в селезеночную вену, а затем - в воротную. Публикаций, в которых описывается применение такого доступа для лечения осложнений трансплантации печени, интрапортальных инфузий, ЭВВВ, немного $[4,5]$. Однако разнородность групп и небольшое количество пациентов не позволяют сделать однозначные выводы о простоте и безопасности селезеночного портального доступа.

Цель исследования: на основании анализа собственного опыта применения селезеночного портального доступа определить его возможности в качестве альтернативы контрлатеральному чреспеченочному доступу.

\section{Материалы и методы иследования}

В период с 2009 по 2017 г. выполнено 475 предоперационных ЭВВВ у пациентов с очаговыми заболеваниями печени. Все пациенты являлись кандидатами на 
обширную резекцию печени, расчетный остаточный объем печени был меныше минимальных пороговых значений: 20\% - для здоровой печени, 30\% - для постхимиотерапевтических изменений, 40\% - для цирроза. Ипсилатеральный портальный доступ выполнили у 323 (68\%) пациентов, контрлатеральный интрапортальный доступ - у 134 (28,2\%). У 18 (3,8\%) пациентов в связи с выраженной деформацией внутрипеченочных портальных ветвей чрескожная чреспеченочная пункция оказалась неудачной либо была расценена как опасная в плане возникновения постпункционного кровотечения. У пациентов с невозможностью интрапеченочного доступа рассматривали возможность экстрапеченочного селезеночного портального доступа. У 11 пациентов (2,3\% от общего числа пациентов, 61,1\% от числа пациентов, у которых интрапеченочный доступ был невозможен) размеры и положение селезенки, проходимость селезеночной вены согласно данным ультразвукового исследования давали возможность безопасной пункции внутриселезеночной венозной ветви. Всем 11 пациентам была выполнена успешная пункция селезеночной вены иглой Chiba $21 \mathrm{G}$ под ультразвуковым контролем. Положение иглы в просвете вены верифицировали с помощью аспирации крови с последующим введением в просвет контрастного вещества. В просвет иглы вводили проводник с последующей установкой интродюсеpa 5 - 6 F. Для портографии и последующей эмболизации целевых портальных ветвей использовали катетер Cobra либо Simmons, в качестве эмболизирующих материалов - полиуретановые эмболы и металлические спирали. Для оценки эффективности эмболизации применяли чрескатетерную и заключительную портографию, выполняли прямое измерение портального давления до и после эмболизации. У 6 больных после удаления интродюсера в пункционный тракт с целью профилактики кровотечения введена короткая эмболизационная спираль, у 5 спираль не устанавливали в связи с опасностью ее миграции. На место пункции накладывали асептическую повязку.

\section{Результаты}

Все вмешательства расценены как технически успешные: удалось катетеризировать и выполнить окклюзию всех целевых ветвей без интраоперационных осложнений и нецелевой эмболизации. Пункцию после местной анестезии осуществляли в направлении наиболее удобной внутриселезеночной венозной ветви, для достижения устойчивого положения иглы в ее просвете требовалось от 1 до 4 попыток. Как правило, пациенты не испытывали значительного болевого синдрома ни во время пункции, ни во время проведения эндоваскулярного инструментария. У 2 больных возникли затруднения проведения проводника в связи с выраженной извитостью селезеночной вены, преодолеть которые удалось при помощи гидрофильного коронарного проводника с последующей установкой по нему трансрадиального интродюсера. Гидрофильные проводники также использовали при затруднениях проведения катетера в деформированные целевые портальные ветви. В целом значимых затруднений для манипуляций инструментарием и проведения эмболизирующих веществ и устройств не было. Интраоперационные и ближайшие послеоперационные осложнения не возникли ни у пациентов, которым пункционный канал закрывали спиралью, ни у пациентов, которым такую окклюзию выполнить не удалось.

\section{Обсуждение}

Селезеночный портальный доступ можно считать достаточно простым и безопасным. Применение его обосновано прежде всего у пациентов, которым интрапеченочный портальный доступ выполнить невозможно изза резкой деформации портальных ветвей либо опасности последующего кровотечения или диссеминации опухолевого процесса в результате проведения инструментария через очаг опухоли. Однако этот доступ имеет некоторые ограничения, связанные с размерами и положением селезенки. В целом, исходя из нашего опыта, безопасную пункцию селезенки можно выполнить у $61 \%$ пациентов, нуждающихся в такой манипуляции. Частота интрапеченочного портального доступа составляет 96,2\%. В отличие от интрапеченочного доступа, селезеночный доступ не сопровождается значительным болевым синдромом, прямое положение инструментария не вызывает затруднений ни для манипуляций катетером, ни для проведения через его просвет эмболизатов. Это дает основания рассматривать селезеночный портальный доступ как альтернативу контрлатеральному интрапеченочному доступу, при котором повреждается паренхима планируемого печеночного остатка, что может отрицательно повлиять на последующую его викарную гипертрофию.

\section{Выводы}

1. Экстрапеченочный селезеночный доступ является миниинвазивным, безопасным портальным доступом и может быть рекомендован к применению у пациентов, нуждающихся в предоперационной ЭВВВ, у которых интрапеченочный портальный доступ невозможен либо связан с высокой опасностью осложнений.

2. Эстрапеченочный селезеночный доступ возможен у 61\% пациентов, нуждающихся в такой манипуляции, что связано с индивидуальными анатомическими особенностями селезенки.

3. Применение гидрофильного инструментария и трансрадиальных интродюсеров значительно облегчает проведение катетера в воротную вену из селезеночного доступа.

4. Закрытие пункционного хода спиралью, согласно нашим данным, не влияет на вероятность развития послеоперационного кровотечения, однако этот вывод нуждается в подтверждении результатами исследований больших групп пациентов.

\section{References}

1. Kubota K, Makuuchi M, Kusaka K. Measurement of liver volume and hepatic functional reserve as a guide to decision-making in resectional surgery for hepatic tumors. Hepatology. 1997;26:1176-81. DOI: 10.1053/jhep.1997.v26.pm0009362359.

2. Abulkhir A, Limongelli P, Healey AJ, Damrah O, Tait P, Jackson J, et al. Preoperative portal vein embolization for major liver resection: a meta-analysis. Ann Surg. 2008 Jan;247(1):49-57. DOI: 10.1097/ SLA.0b013e31815f6e 5b. 
3. May BJ, Talenfeld AD, Madoff DC. Update on portal vein embolization: evidence-based outcomes, controversies, and novel strategies. J Vasc Interv Radiol. 2013;24:241-54. doi: 10.1016/j.jvir.2012.10.017.

4. Ko HK, Ko GY, Sung KB, Gwon DI, Yoon HK. Portal Vein Embolization via Percutaneous Transsplenic Access prior to Major Hepatectomy for Patients with Insufficient Future Liver Remnant. J Vasc Interv Radiol. 2016 Jul;27(7):981-6. doi: 10.1016/j.jvir.2016.03.022.
5. Chu HH, Kim HC, Jae HJ, Yi NJ, Lee KW, Suh KS, et al. Percutaneous transsplenic access to the portal vein for management of vascular complication in patients with chronic liver disease. Cardiovasc Intervent Radiol. 2012 Dec;35(6):1388-95. doi: 10.1007/s00270-011-0311-y. 